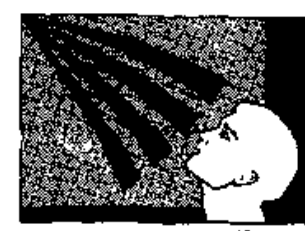

FORMACAOO DOPSICÓLOGO

\title{
A visão dos alunos sobre sua formação
}

Ana Maria de Almeida Carvalho, professora do Departamento de Psicologia Experimental do Instituto de Psicologia da USP, está desenvolvendo bá cerca de 5 anos uma pesquisa sobre formação. No depoimento a seguir, ela apresenta os resultados parciais ressaltando os aspectos mais relevantes constatados até agora:

“ m 1978 eu dava aulas de Psicologia Geral já há uns cinco anos, e estava inquieta com o curso. Tiaha o sentimento de que não entendíamos o processo de formaçāo, não tínhamos uma visão de conjunto do curso, não sabíamos direito qual o papel que desempenhava cada disciplina no currículo, quem era o aluno que estava sendo formado; eu estava, enfim, num momento de questionamento protissional. Juntava-se a isso o fato de que nessa matéria discutíamos o problema da atuaçāo do psicólogo e do mercado de trabalho, usando o livro da Sylvia Leser de Mello (Psicologia e Profissão em Sảo Paulo, Ática), baseado numa pesquisa que nessa altura já tinha quase 10 anos. Os alunos questionavam se esse material já não seria antigo, e se as condiçōes não teriam mudado desde então.

Maria Alice Leme e eu resolvemos então usar o espaço do curso de Psicologia Geral para os próprios alunos coletarem informaçōes a respeito da profissão, como uma experiência de pesquisa dentro da disciplina. Montamos um esquema para que, durante $S$ anos, os alunos entrevistassem um certo número de psicólogos. Paralelamente, resolvi acompanhar, em termos longitudinais, um grupo de 20 alunos, durante os cinco anos do curso, através de uma entrevista anual, pensando em obter um material mais qualitativo a respeito do processo de formação.

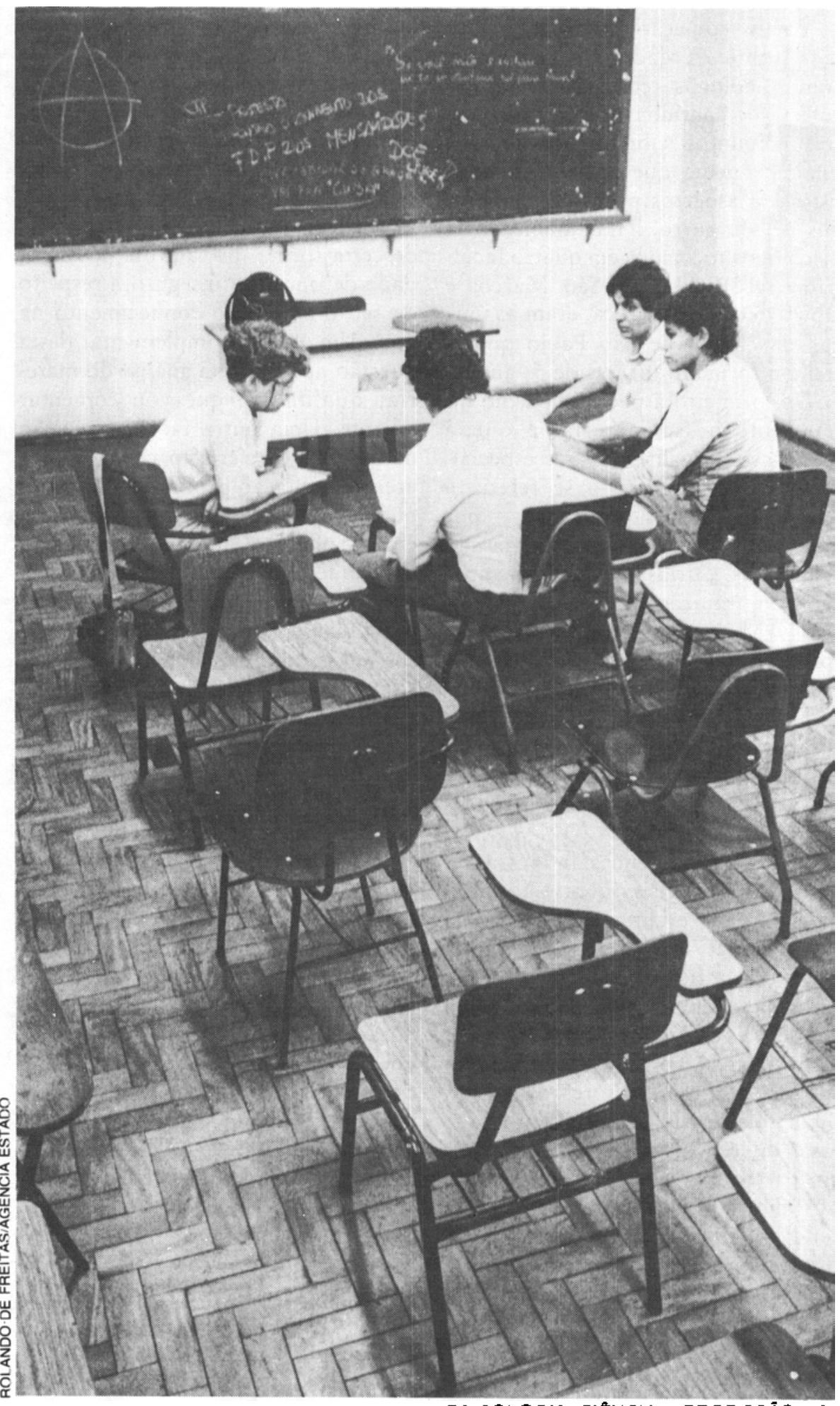


Tenho, portanto, essas duas fontes de material. A primeira está analisada e praticamente esgotada, sendo que seus resultados constam em artigos publicados e relatórios. A segunda fonte ainda está bastante crua, e, embora eu já tenha apresentado alguns aspectos dos resultados em trabalhos preparados para congressos, ainda não tenho uma análise sistemática de todos os temas que me propus a explorar.

Vamos começar com uma análise feita sobre os dados de entrevistas com psicólogos recém-formados. A entrevista continha apenas duas ou três perguntas sobre formação, nas quais se pedia que os entrevistados listassem aspectos positivos e negativos de seu curso. Trabalhamos com psicólogos formados em quatro faculdades: USP, PUCSP, São Marcos e Objetivo que, na época, eram as únicas da cidade de São Paulo que já tinham formado turmas de $5^{\circ}$ ano.

Um primeiro aspecto que acho interessante nesse material $\dot{e}$ que a maioria das avaliações - e especialmente as negativas - se referia a pontos específicos do curso - por exemplo, as aulas de tal matéria não eram boas. Curiosamente, numa aparente contradiçāo, as avaliaçōes genéricas tendiam a ser positivas: o curso foi ótimo, gostei muito. Parece ser mais fácil uma atitude crítica em relação a aspectos particulares do curso do que ao seu conjunto; ou, complementarmente, talvez numa visão retrospectiva os aspectos positivos tendam a ser ressaltados.

Algumas diferenças interessantes apareceram entre as quatro faculda. des. Na USP, e também em parte na PUC, muitas avaliaçōes se referiam à formação crítica e base teórica oferecidas pelo curso, enquanto na São Marcos e Objetivo foram mais comentadas as condições de ensino (qualidade dos professores, disponibilidade de material, etc). Penso que essas diferenças indicam, pelo menos em parte, uma certa heterogeneidade dos alunos dos vários cursos, que se reflete no uso de critérios de avaliação diferentes. Esse ć um ponto que me parece importante na análise deste tipo de material: é preciso lembrar, ao trabalhar com dados de entrevista deste tipo, que os resultados refletem 20 PSICOLOQIA, CIEANCIA E PROFISSÁO tanto o que é avaliado (no caso, o curso) quanto os avaliadores (que, aliás, são em alguma medida fruto do avaliado...)

Outro aspecto levantado se refere ao conteúdo das avaliaçōes em termos de formação teórica, prática ou técnica. Encontrou-se muito pouca referência à formaçāo técnica. A maior parte das referências verificou. se para formação teórica, e em geral com um tom positivo. A prática foi mais freqüentemente considerada de forma negativa.

Em termos de queixas, verificou-se uma certa porcentagem a respeito de contato restrito com orientaçôes teóricas diferentes. $O$ aluno exposto basicamente a uma ou poucas das vertentes teóricas da Psicologia se sente, de certa forma, privado da possibilidade de opção, $\mathrm{e}$ inseguro a respeito de seu domínio do conhecimento na área. Um ângulo complementar desta questão apareceu na análise do material qualitativo, que vou comentar adiante. Uma outra face da questão da opção se refere ao contato com áreas de atuação profissional: foi freqüente a queixa de que nāo havia ênfase suficiente em diversas áreas; ao mesmo tempo, $o$ aprofundamento em uma área é avaliado positivamente. Isto pode ser traduzido assim: os cursos em geral enfatizam muito a área clínica, e faz falta a formação em outras áreas; mas a formação em clínica é considerada boa. A existência de opções é muito valorizada, mas os alunos não querem que se reduza, de nenhum modo, o que é oferecido. De certa forma, então, a expectativa é de que o curso possa ser onipotente e realizar maravilhas em todas as áreas possíveis da Psicologia. Uma situaçāo de certa forma análoga, e relacionada com esta, ocorre em relação à carga horária dos cursos: na USP e PUC, a queixa é de que a carga horária é excessiva (horário integral); nas outras duas taculdades, os alunos se queixam de que a carga horária $\varepsilon$ insuficiente para cobrir todos os conteúdos e experiências necessários...

Em síntese, esse material sugeriu alguns pontos interessantes para se refletir sobre a formação. Dada a natureza do material, no entanto, muita coisa é difícil de interpretar: as respostas tenderam a ser muito genéri- cas, nāo foram aprofundadas, em função das características e objetivos do roteiro de entrevista, e a provável heterogeneidade dos respondedores e de seus critérios introduz variaçōes que dificultam a análise. Em última instância, pode ser que essas varia. ções reflitam também a ausência de um consenso sobre o que deve ser um bom curso de formação.

A outra parte da pesquisa são as entrevistas mais aprofundadas ou qualitativas que fiz com alunos do IPUSP, ao longo de cinco anos. Embora não tenha ainda analisado todo esse material, alguns pontos podem ser comentados. Por exemplo, estou convencida, a partir do que encontrei nesse trabalho, de que a diversidade de enfoques teóricos no curso é extremamente positiva, num sentido de FORMAÇÃO, e não só de informação ao aluno sobre possibilidades de opção. Embora essa exposição a pontos de vista diferentes e até opostos seja muito conflitante e sofrida para 0 aluno, esse conflito me parece ser muito construtivo para que ele chegue a formar um pensamento crítico, a ter uma visão da Psicologia como o resultado, em construção, de um PROCESSO de produção de conhecimen. to. Mais do que as declarações de que o conhecimento está em construção, nas aulas de Psicologia Geral, ou de Metodologia Científica, penso que o que dá essa consciência ao aluno são a experiência e a vivência com a diversidade teórica ao longo do curso, e a necessidade de lidar com ela. É evidente que essa experiência pode ser mais ou menos produtiva e eficiente, dependendo de como se dá o contato com as várias possibilidades teóricas da Psicologia, da própria atitude dos professores a respeito dessa questão, $e$ de outros fatores, circunstanciais.

Um ponto relacionado a este se refere à formação em pesquisa. Ao analisar o material, fiquei muito surpresa por constatar como o aluno chega ao curso sem noção do que é pesquisa ou do que é ciência.

'Eu não imaginava que, quando entrasse na faculdade, eu ia ficar questionando, entende? Eu achava que ia chegar lá e ia ter uma aula a respeito... Eu achava que tinha UNS POUCOS que estudaram aquilo e já tinham tudo assim certinho. Eu não 
imaginava esse negócio assim de pesquisa, sabe?"

Este é um depoimento de um aluno do $1^{\circ}$ ano, e não é o único nesses termos. De uma forma mais ou menos sofisticada, encontrei essa concepção de que Psicologia é um conhecimento pronto, que vai ser adquirido na faculdade. Penso que esta é uma concepçāo extremamente negativa para a formação do psicólogo, que, de todas as maneiras, os cursos deveriam desencorajar e modificar. Em parte, me parece que os cursos conseguem isso, mas ainda há muito por se fazer no sentido de preparar o aluno como pesquisador — não necessariamente para uma atuação específica em pesquisa. mas como uma parte da formaçāo profissional que considero fundamental para qualquer ripo de atuaçāo. Penso que através de uma boa formaçāo em pesquisa, podemos formar um profissional que vai atuar em qualquer área, com uma atitude de pesquisador. A necessidade de melhorar esse aspecto da formação é um dos resultados que mais chama a atenção, tanto no meu material, como nos dados quantitativos colhidos pela pesquisa do Conselho Federal de Psicologia, e publicados recentemente 1"Quem é o psicólogo brasileiro". Edicon, 1988).

Do ponto de vista da formaçāo prática e dos estágios, no início do curso, os alunos se queixavam de ter pouco contato com a realidade, de ter poucos estágios; ao mesmo tempo, havia uma certa "consciência" de que era cedo, um medo de se deparar com uma situação em que precisassem intervir sem ainda estarem preparados. $\mathrm{Na}$ medida em que vào avançando no curso, no $3^{\circ}$ ano, por exemplo, os alunos da USP têm alguns estágios que sảo exeperiências extremamente fortes para eles; no entanto, em vários casos, há uma falta de continuidade. Por exemplo, um aluno me diz, a respeito de um estágio em instituiçāo, que foi ótimo, e muito rico, mas que se tivesse durado mais seis meses ele nảo saberia mais o que fazer ali dentro - a perspectiva de atuação parece que não chega a se concretizar nessas experiências. No curso da USP, o único estágio que, nessa ocasiāo, os alunos relatavam como algo com continuidade, era o estágio de atendimento

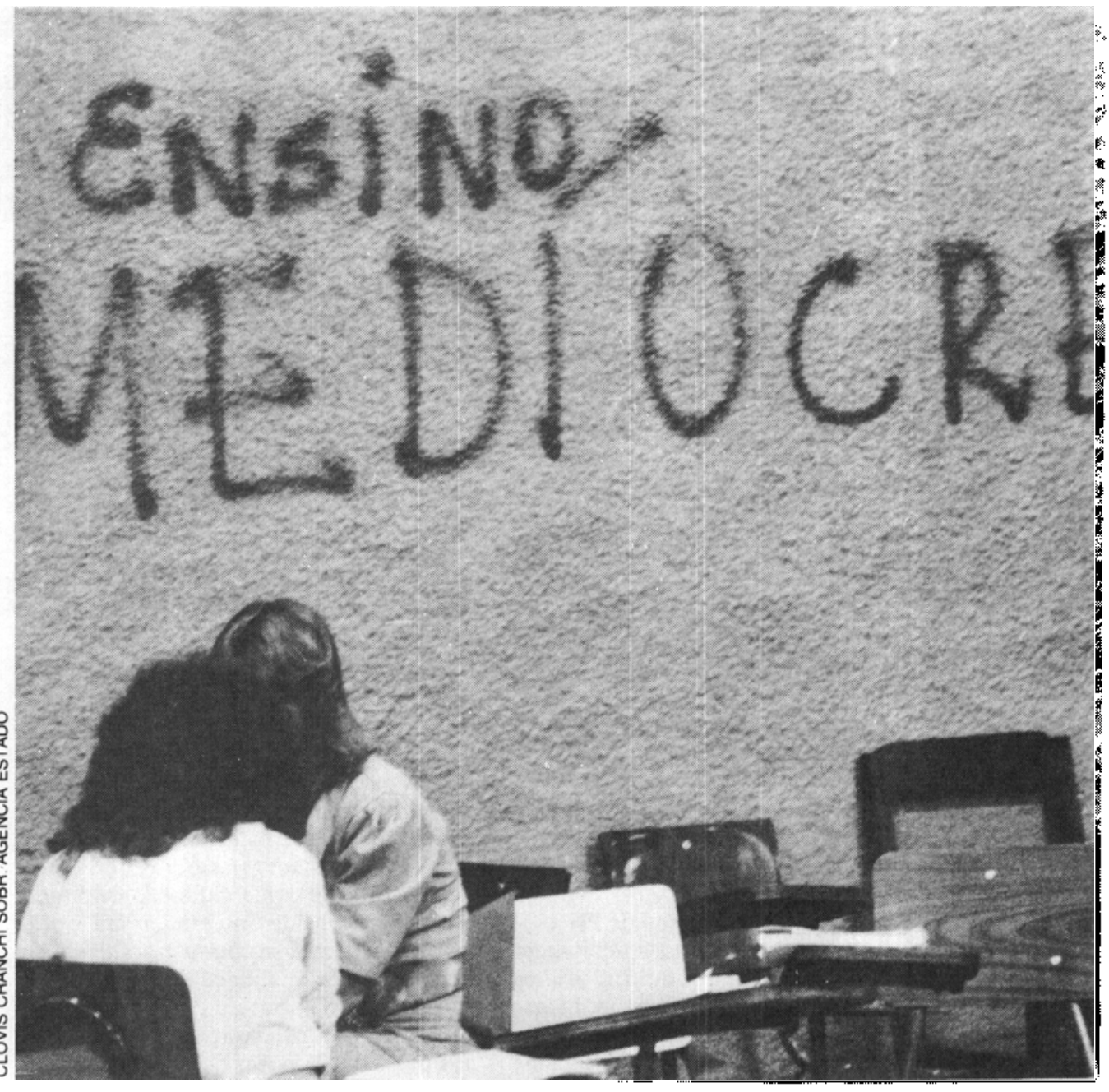

clínico individual. Embora eles tivessem alguma experiência clínica com excepcionais, grupos, etc., o atendimento individual era o mais marcante, talvez porque fosse uma atuaçāo efetiva, com supervisão intensiva e em geral bem avaliada. Mesmo considerando que eles atendiam apenas 2,3 ou 4 casos ao longo de dois anos, era. um trabalho que pareciam ter vivido o suficiente para terem, inclusive, a consciência de que ainda tinham muito que aprender, e para se sentirem engrenados, envolvidos, motivados para essa aprendizagem.

Não tenho uma idéia formada sobre como melhorar os estágios, ou como desenvolver estágios satisfatórios em todas as áreas possiveis. Tenho muitas dúvidas sobre se o caminho adequado para melhorar a formaçào é carregar basicamente na parte de estágios - inclusive porque esse caminho me parece dos mais difíceis na prática, e, entre essas dificuldades, uma das mais importantes, pelo que deduzo dos depoimentos de meus alunos, é a disponibilidade de supervisores ou professores com alta qualidade didática e de experiência; como ensinar o que ainda não existe ou não está feito? Minha impressāo é que o caminho de uma boa formação deve ser no sentido de formar um profissional capaz de criticar, analisar, reformular, inventar, PENSAR a situação colocada para ele. Ele deve atuar com base num corpo de conhecimentos especí. ficos, mas não é um técnico aplicador de procedimentos aprendidos. Acho que precisamos de uma formaçāo que capacite e leve o aluno a pensar em cada teoria e em cada experiência de atuação, refletindo sobre o que é o PSICOLÓGICO com o qual cada um está lidando, e abstraia um conceito de psicológico que não se define pelo uso de uma técnica $X$ em uma situação Y, mas pela natureza dos fenômenos trabalhados. Penso que esse é o profissional capaz de contribuir para a diversificação e ampliação da Psicologia como profíssão." 